\title{
Low level of objectively measured physical activity and cardiorespiratory fitness, and high prevalence of metabolic syndrome among Pakistani male immigrants in Oslo, Norway
}

\author{
Eivind Andersen ${ }^{1}$, Arne Torbjørn Høstmark ${ }^{1}$, Catherine Lorentzen ${ }^{2}$ and Sigmund Alfred Anderssen ${ }^{1}$ \\ 1) Department of Sport Medicine, Norwegian School of Sport Sciences, Ullevaal Stadium, Box 4014, 0806 Oslo, Norway \\ 2) Department of health promotion, Faculty of Health Sciences, Vestfold University College, Box 2243, 3103 Tønsberg, Norway \\ Correspondance: eivind.andersen@nih.no, phone +4723262449
}

\begin{abstract}
Background: The level of physical fitness in south Asian immigrants living in Norway is largely unknown, but the level of physical activity seems to be low, possibly in part explaining their high prevalence of diabetes and cardiovascular diseases. However, previous studies have used self-reported measures of physical activity, and it might be questioned whether the previous data reflect the true physical activity level.

Aim: To describe objectively measured physical activity level, cardiorespiratory fitness and diabetes risk in a group of Pakistani immigrant men living in Oslo, Norway.

Methods: One hundred and fifty Pakistani immigrant men in the age group 25-60 years were included. Physical activity level was assessed with an accelerometer. Cardiorespiratory fitness was measured until exhaustion on a treadmill, and diabetes risk was evaluated with an oral glucose tolerance test.

Results: Mean age was 37.3 years $(\mathrm{SD}=7.7)$. Total physical activity level was 308 counts/min $(\mathrm{SD}=131)$, and peak oxygen uptake was $34.2 \mathrm{ml} \cdot \mathrm{kg}^{-1} \cdot \mathrm{min}^{-1}(\mathrm{SD}=5.6)$. Fifty percent of the participants had the metabolic syndrome, and $76 \%$ were obese. Physical activity level and cardiorespiratory fitness level were lower, and prevalence of the metabolic syndrome higher in a subgroup of taxi drivers as compared with those in other occupations $(\mathrm{P}<0.05)$.
\end{abstract}

Conclusions: Physical activity and cardiorespiratory fitness levels are low and diabetes risk high among Pakistani immigrant men living in Oslo, especially in taxi drivers.

\section{INTRODUCTION}

People with the metabolic syndrome (MetS), a cluster of metabolic risk factors, are at high risk for developing Type 2 diabetes (T2D) and cardiovascular diseases (1). In particular, people from south Asia seem to have a high risk (2-5). Results from the "Romsås in motion" project in Oslo demonstrated a higher prevalence of self reported T2D among people from south Asia compared to ethnic Norwegians (6). The reason for this high prevalence of T2D is not known, but might be partly explained by susceptibility towards developing insulin resistance $(7,8)$. A low level of physical activity (PA) has been observed among the south Asians in Norway (9) and this could play a key role since physical inactivity is a major cause for the development of T2D and is believed to be at the core of the MetS (10). Furthermore, the observed higher occurrence of disease among south Asian immigrants in Western countries compared with their siblings living in their home country (11) underlines the important role of unhealthy lifestyle as a crucial determinant of non-communicable diseases (not contagious diseases), such as T2D.

Since the prevalence and burden of T2D and cardiovascular diseases are especially high among south Asian immigrants in Western societies, and PA can beneficially influence T2D and cardiovascular diseases, special attention to the PA level of this population group is needed. Although studies consistently show a low level of PA among Non-Western immigrants in
Norway and other Western countries (12-14), the results may be flawed by the use of self reported methods when collecting PA data. These methods carry certain weaknesses. Immigrants may find it difficult to fill in questions that are not presented in their mother tongue and they could have different perception about the PA term. In addition, the questionnaires used are often not tested for validity on immigrants. It is also difficult to obtain a precise description of the activity pattern during the day, and differences between weekdays and weekends using existing questionnaires. In addition, accurate information about duration and intensity of the activity is a problem. These are all methodological issues that can be overcome by the use of objective measurements such as an accelerometer. To our knowledge there are no papers giving objectively measured PA level in immigrants, and physical fitness is largely unknown. Based on aforementioned limitations in existing research and since physical activity seems to be crucial in the prevention of MetS/T2D, our first aim of this paper was to describe objectively measured PA pattern, cardiorespiratory fitness and diabetes risk in a group of Pakistani immigrant men living in Oslo, Norway. Furthermore, others have shown that taxi drivers are a particularly vulnerable group, expressing high coronary risk (15) and a low average expected life time (16). Our second aim was therefore to describe the physical activity pattern, cardiorespiratory fitness and diabetes risk in a subgroup of male Pakistani immigrant taxi drivers. 


\section{MATERIALS AND METHODS}

The data presented in this paper are the baseline results from the "Physical activity and minority health study" which was designed as a randomized controlled trial with the main goal to increase the participants PA level.

\section{Participants}

Men living in Oslo, Norway, with a Pakistani background (either born in Pakistan or parents born in Pakistan) in the 25-60 year age group who were not very physically active (exercising at the most twice a week at a moderate or higher intensity level for $30 \mathrm{~min}$ or more at a time, or were active commuters) were candidates for inclusion in this study. Immigrants from Pakistan were chosen as the target group in this study because they are the largest immigrant group from south Asia in Norway $(n=31061$ (17)). The recruitment process was carried out during the autumn of 2008 . We gave a brief oral presentation concerning the project at six mosques and at various Muslim festivals in Oslo. One hundred and eighty two men volunteered for participation in the study and of these 32 failed to meet the inclusion and exclusion criteria, giving 150 participants. Reasons for exclusion were known diabetes $(n=10)$, being too physically active $(n=8)$, not being able to communicate in Norwegian $(n=7)$, too old $(n=5)$ and having a severe injury $(n=2)$. Before participation in the study, written informed consent was obtained from each participant. The Regional Committee for Medical Research Ethics (ref. no. S-07300b) and the Norwegian Social Science Data Services (ref. no. $17212 / 2 / \mathrm{KS}$ ) both approved the study.

\section{Measurements}

The tests were carried out at the Norwegian School of Sport Sciences from October to November 2008. Waist circumference was measured, in the standing position and after a light expiration, in a straight line to the chest midway between the lower rib margin and the iliac crest. Weight was measured without shoes in light clothing by a SECA electronic scale (SECA model 767 , Germany) to the nearest $0.5 \mathrm{~kg}$. Height was measured without shoes with a transportable stadiometer (Harpenden; Holtain, Crymych, GB) and set to the nearest $0.5 \mathrm{~cm}$. Body mass index (BMI) was calculated as weight divided by height squared $\left(\mathrm{kg} / \mathrm{m}^{2}\right)$. Blood pressure was measured automatically using an Omega non-invasive blood pressure monitor (Invivo Research, Inc., Orlando, FL, USA) in the morning after the participant had rested for $10 \mathrm{~min}$ in a quiet room. Three consecutive blood pressure measurements were performed with 1 min rest between each measurement. Blood pressure was recorded as the average value of the three recordings.

\section{Physical activity}

Habitual PA was assessed with an Actigraph accelerometer (MTI model 7164; Manufacturing Technology Inc., Fort Walton Beach, FL, USA). This is a seismic instrument which continuously measures acceleration in the vertical plane, and raw data from this instrument are called "counts", which are the sum of acceleration in a given time period. The participants were instructed to wear the accelerometer for seven days on the right hip during all waking hours, except while swimming and bathing. Accelerometers were programmed to start recording at 6 am the day after the participants received their accelerometer.

The epoch length (sample interval) was set to one minute. In the analysis of accelerometer data, epoch periods with a value of zero, with two exceptions, for $60 \mathrm{~min}$ or longer were interpreted as "accelerometer not worn" and excluded from the analysis (18). PA data were further included if the participant had accumulated a minimum of $480 \mathrm{~min}$ of activity data per day. There were no differences in total physical activity (counts/min) between those who wore the monitor for two days and those who wore the monitor for three days or more. For that reason, also those participants who had worn the monitor for two days $(n=7)(19)$ were included. Participants wore the monitor for a mean of 6.3 days $(\mathrm{SD}=1.8)$. Average wearing time was 13.5 hours/day $(\mathrm{SD}=1.5)$. Accelerometer data were processed and analyzed using the SAS-based (version 9) software program (SAS Institute Inc. Cary, North Carolina, USA) called CSA-analyzer (http://csa. svenssonsport.dk). One hundred and forty two participants had valid recordings. Four lost their monitor and four had less than two valid days of recordings. The primary outcome variable from the accelerometers is the average counts/min throughout the measurement period. Secondary outcomes are the minutes spent in various levels of PA intensity in which sedentary behavior (inactive time) was defined as $\leq 100$ counts $/ \mathrm{min}$ (20), light intensity activity as 101-1951, moderate intensity as 1952-5724, vigorous intensity as 57259497 and any amount above 9497 was considered very vigorous intensity (21). These cut points are widely used and show a good correlation $(\mathrm{r}=0.88)$ with direct $\mathrm{VO}_{2}$ measurement (21). To reach the recommended level of PA one has to undertake at least $30 \mathrm{~min}$ of moderate to vigorous PA (MVPA) per day. The $30 \mathrm{~min}$ can be split into bouts of $10 \mathrm{~min}$. A bout was defined as $10 \mathrm{~min}$ or more consecutive $\min$ above 1952 counts/min with allowance for interruption of 1 or 2 min below threshold, to allow for small breaks in the activity (e.g. stop for red light).

\section{Cardiorespiratory fitness}

Cardiorespiratory fitness or Peak $\mathrm{VO}_{2}$, defined as the highest measured $\mathrm{VO}_{2}\left(\mathrm{ml} \cdot \mathrm{kg}^{-1} \cdot \mathrm{min}^{-1}\right)$, was assessed through a maximum exercise test on a treadmill. We used a modified Balke protocol (22). Gas exchanges were continuously sampled in a mixing chamber every $30 \mathrm{~s}$ by breathing into a Hans Rudolph two-way breathing valve (2700 series, Hans Rudolph Inc, Kansas City, USA). The breathing valve was connected to a Jaeger Oxycon Pro (Erich Jaeger GmbH, Hoechberg, Germany) used to analyze the oxygen and carbon 
Table 1. Summary of psychosocial variable measurements.

\begin{tabular}{lccc}
\hline Variable & $\begin{array}{c}\text { Number of items/ } \\
\text { response format }\end{array}$ & $\begin{array}{c}\text { Original reference source on } \\
\text { which items were based }\end{array}$ & $\begin{array}{c}\text { Cronbach`s } \\
\text { alpha }\end{array}$ \\
\hline $\begin{array}{l}\text { Social support } \\
\text { - family }\end{array}$ & $6 / 1$ (never) - 5 (very often) & $(26)$ & 0.85 \\
- friends & & & 0.88 \\
Self-efficacy & $7 / 1$ (not at all confident) - & $(27)$ & 0.88 \\
& (extremely confident) & & \\
Attitude & & $(28,29)$ & 0.90 \\
- Evaluative & $5 / 1-7$ & & 0.79 \\
- Affective & $3 / 1-7$ & $(29)$ & 0.62 \\
Behavioural control & $3 / 1-7$ & $(30)$ & 0.74 \\
Identity & $3 / 1$ (suits badly) -5 (suits well) &
\end{tabular}

content. The analyzer was volume- and gas-calibrated before each test. Test results was approved when scoring $\geq 16$ on the Borg scale and when respiratory quotient was $>1.1$. For security reasons we tested only those under the age of 40 years $(n=99)$.

\section{Blood samples}

After a 12-h overnight fast (minimum $8 \mathrm{~h}$ ), between 0800 and 1030 hours, venous blood samples were drawn from an antecubital vein. Blood samples were mechanically agitated for $30 \mathrm{~min}$ to prevent clotting, and were then aliquoted and separated. Blood samples were centrifuged for $10 \mathrm{~min}$ at $2500 \mathrm{~g}$. All samples were analyzed at FÜRST Laboratory for clinical chemistry (Oslo, Norway) the same day. An oral glucose tolerance test was performed, i.e. 75 g glucose in 200 $\mathrm{ml}$ of water was ingested and plasma glucose and insulin were determined before and two hours after ingestion of the glucose drink. A Modular P Machine (Roche, Japan) was used for measuring HDL cholesterol (immuno-turbidometric assay), LDL cholesterol (direct enzymatic method), triglycerides (enzymatic assay), glucose (photometric) and insulin (immunoassays).

\section{Assessment of insulin resistance}

The degree of insulin resistance was estimated by HOMA (homeostasis model assessment) according to the method described by Matthews et al. (23). Insulin resistance score (HOMA-IR) was computed with the formula: (fasting plasma glucose $x$ fasting serum insulin)/22.5. Low HOMA-IR values indicate high insulin sensitivity, whereas high HOMA-IR values indicate low insulin sensitivity (insulin resistance).

\section{Metabolic syndrome and diabetes}

Metabolic syndrome was defined according to the criteria set by the international diabetes federation (10), and diabetes, impaired fasting glucose and impaired glucose tolerance are defined according to the criteria set by the American Heart Association (24).

\section{Questionnaire data}

The questions were available in both Norwegian and Urdu. If a question was unclear the participants had the possibility to ask the test staff for help. The questions covered a broad range of themes, including demographic information, health status, diet, physical activity participation and psychosocial determinants of physical activity.

\section{Psychosocial determinants}

The following potential psychosocial determinants of physical activity were measured: social support, selfefficacy, attitude, behavioural control, and identity. Measurement descriptions of these variables are summarized in Table 1. All scales were derived or modified from previously developed and validated scales (see Table 1), and additional exploratory factor analyses (principal components analysis with varimax rotation) were performed. A two-factor solution was found for the attitude scale, representing evaluative ( 5 items) and affective (3 items) aspects of attitude. These two factors accounted for $74.0 \%$ of the total variance. The mean score of all belonging items was computed for each scale/subscale, including participants with a response rate of $75 \%$ or greater on the respective items (25). Higher scores indicated a greater psychosocial readiness for physical activity. Generally, internal consistency properties were found satisfactory (see Table 1). Information about barriers towards PA was asked with the question; "Range how relevant the listed barriers is for you". The scale went from zero (not a barrier) to 5 (very relevant).

\section{Food and cola}

Information about the intake of fruits, vegetables, fish and colas was obtained using the question: "Think back on the last 14 days. How often have you been eating/drinking...?" Participants were asked to indicate on a 6-point scale, ranging from "not been eating/ drinking" to "daily", for fish and colas. For fruits and vegetables the scale also included daily frequencies with the alternatives 1,2 and 3 times/day. In the analyses the categories "not been eating/drinking" and " $<1$ time/week" were consorted into one, also the categories "3-4 times/week" and "5-6 times/week" were consorted. Sugar intake was calculated as the sum of frequencies with intake of sodas, juice, fine bread, rice, pasta, jam, chocolate and snacks per week. 


\section{Statistical analysis}

All statistical analyses were performed using SPSS (Statistical Package for the Social Sciences for Windows, version 15, IBM Inc. Chicago, USA). Descriptive data are presented as means, proportions and standard deviations (SD). Differences between mean values of interval data were evaluated by independent samples t-test. The results are presented as mean differences between the two groups \pm confidence intervals (CI). When assessing the risk of having the MetS, we used logistic regression with MetS as the dependent variable and occupation as the independent variable under investigation, adjusted for age and education level.

\section{RESULTS}

\section{Participants}

Of the 150 participants included, 124 (83\%) were not born in Norway (first generation immigrants). On average, the first generation immigrants had lived in Norway for 20 years (range 1 to 38 years). One hundred and forty three were employed (95\%) and $54 \%$ had college education (Table 2). Furthermore, 93\% and $81 \%$ were classified as overweight according to BMI $\geq 23$ (31) and waist circumference $\geq 90 \mathrm{~cm}$ respectively (10).

\section{Physical activity and cardiorespiratory fitness}

Of the 142 participants with complete accelerometer data, only six (4.2\%) reached the PA recommendations of 30 min of MVPA per day (PA bouts had to be of at least 10 min duration or more). Total PA level (counts/ min) ranged from 86 to 847 (Table 3). There were no differences in PA between workdays and weekends. The participants spent $63 \%$ of the waking day in sedentary time (range $36 \%$ to $80 \%$ ). There were no differences in any of the PA variables between the first and second generation immigrants. Peak oxygen uptake ranged from $23.4 \mathrm{ml} \cdot \mathrm{kg}^{-1} \cdot \mathrm{min}^{-1}$ to $49.1 \mathrm{ml} \cdot \mathrm{kg}^{-1} \cdot \mathrm{min}^{-1}$. Twenty participants had a peak oxygen uptake less than $30 \mathrm{ml} \cdot \mathrm{kg}^{-1} \cdot \mathrm{min}^{-1}$ and 15 had an oxygen uptake above $40 \mathrm{ml} \cdot \mathrm{kg}^{-1} \cdot \mathrm{min}^{-1}$.

\section{Metabolic syndrome and carbohydrate metabolism}

Table 4 shows the number of participants with normal and abnormal carbohydrate metabolism and the MetS. Mean fasting $(5.3 \mathrm{mmol} / \mathrm{l}(\mathrm{SD}=0.9))$ and postprandial $(6.9 \mathrm{mmol} / \mathrm{l}(\mathrm{SD}=2.9))$ glucose levels were within the normal range, but insulin-2h levels were very high $(796 \mathrm{pmol} / \mathrm{l}(\mathrm{SD}=587))$ and $74 \%$ were classified as insulin resistant (HOMA-IR > 2.5 (32)). Participants with the MetS had $3.1 \mathrm{ml} \cdot \mathrm{kg}^{-1} \cdot \mathrm{min}^{-1}(\mathrm{P}=0.004 ; 95 \% \mathrm{CI}$ $=1.0$ to 5.2$)$ or $9 \%(95 \% \mathrm{CI}=3.3$ to 14.6$)$ lower peak oxygen uptake compared to those without the MetS. There was no difference between those with and without the MetS with respect to sugar intake, age or any of the PA variables. Ninety five participants had a family member with diabetes. Of these, 42 participants
Table 2. Characteristics of the study population $(n=147-150)$.

\begin{tabular}{|c|c|}
\hline Characteristic & Value \\
\hline Age (years), mean (SD) & $37.3(7.7)$ \\
\hline \multicolumn{2}{|l|}{ Education level, n (\%) } \\
\hline Primary school & $23(15)$ \\
\hline High school & $46(30)$ \\
\hline College less than 3 years & $29(19)$ \\
\hline College more than 3 years & $51(34)$ \\
\hline BMI $\left(\mathrm{kg} / \mathrm{m}^{2}\right)$, mean $(\mathrm{SD})$ & $27.2(3.6)$ \\
\hline Overweight (BMI 23-24.9), (\%) & 16.7 \\
\hline Obese $(\mathrm{BMI} \geq 25),(\%)$ & 76.7 \\
\hline Waist circumference $(\mathrm{cm})$, mean $(\mathrm{SD})$ & $98.2(10.0)$ \\
\hline Triglyceride (mmol/l), mean (SD) & $1.9(1.7)$ \\
\hline HDL cholesterol (mmol/l), mean (SD) & $1.0(0.2)$ \\
\hline LDL cholesterol (mmol/l), mean (SD) & $3.4(0.7)$ \\
\hline Smokers, $\mathrm{n}(\%)$ & $35(23)$ \\
\hline
\end{tabular}

Table 3. Physical activity and physical fitness data $(n=142)$.

\begin{tabular}{lc}
\hline Physical activity and fitness variables & Mean (SD) \\
\hline Total PA (counts/min) & $308(131)$ \\
Total PA workdays (counts/min) & $312(138)$ \\
Total PA weekends (counts/min) & $293(148)$ \\
Inactive time (hours/day) & $8.6(1.6)$ \\
MVPA (min/day) & $32.3(20.8)$ \\
$\quad$ Moderate intensity & $30.4(18.9)$ \\
$\quad$ Vigorous intensity & $1.8(3.6)$ \\
Peak oxygen uptake $\left(\mathrm{ml} \cdot \mathrm{kg}^{-1} \cdot \mathrm{min}^{-1}\right)^{*}$ & $34.2(5.6)$ \\
\hline Values are mean \pm SD; standard deviation \\
*n=99, PA; physical activity, MVPA; moderate and vigorous \\
intensity physical activity
\end{tabular}

Table 4. Carbohydrate metabolism and metabolic syndrome.

\begin{tabular}{|c|c|c|c|}
\hline & \multicolumn{2}{|c|}{ Cut off values } & \multirow[b]{2}{*}{$\mathrm{n}(\%)$} \\
\hline & Fasting & 2-h OGTT & \\
\hline Normal $^{1}$ & $<6.1$ & $<7.8$ & $106(70)$ \\
\hline $\mathrm{IFG}^{1}$ & 6.1 to 6.9 & $<7.8$ & $2(1.3)$ \\
\hline IGT $^{1}$ & $<7.0$ & $\geq 7.8$ and $<11.1$ & $27(18)$ \\
\hline $\mathrm{DM}^{1}$ & $\geq 7.0$ & $\geq 11.1$ & $11(7.3)$ \\
\hline HOMA-IR & & & $4.1(2.4) \dagger$ \\
\hline $\mathrm{MetS}^{2}$ & & & $75(50)$ \\
\hline Indian risk score ${ }^{3 *}$ & $\geq 21$ & & $81(85.3)$ \\
\hline
\end{tabular}

${ }^{1}(24),{ }^{2}(10),{ }^{3}(33)$

$\mathrm{n}=146$ for Carbohydrate metabolism data, $\mathrm{n}=149$ for MetS data, $\mathrm{n}=$ 95 for Indian risk score, $\uparrow$ mean \pm standard deviation, OGTT; oral glucose tolerance test, IFG; impaired fasting glucose, IGT; impaired glucose tolerance, DM; diabetes mellitus, MetS; metabolic syndrome, IDF; International Diabetes Federation, HOMA-IR; homeostasis model assessment - insulin resistance, * A score of 21 (max 42$)$ or above is considered high risk of developing type 2 diabetes. The risk factors are high age, diabetes in the family, overweight and physical inactivity.

had one family member with diabetes, 33 had two, 15 had three and five participants had four members of the family with known diabetes. 
Table 5. Weekly intakes of colas, fruits, vegetables and fish (\%), ( $\mathrm{n}=144-146)$.

\begin{tabular}{lcccc}
\hline Dietary items & Not eaten/drunk & 1-2 times/week & 3-6 times/week & Daily \\
\hline Colas* & 43.8 & 29.2 & 22.9 & 4.2 \\
Fruit & 7.5 & 16.4 & 54.8 & 21.2 \\
Vegetables & 4.8 & 24.7 & 45.2 & 25.3 \\
Fish & 28.3 & 41.4 & 24.8 & 5.5 \\
\hline
\end{tabular}

Data are presented as percentages

* Sugar containing colas

Table 6. Characteristics of the participants according to occupation.

\begin{tabular}{|c|c|c|c|c|}
\hline & $\begin{array}{c}\text { Taxi drivers } \\
(\mathrm{n}=59-73)\end{array}$ & $\begin{array}{l}\text { Other occupations } \\
\quad(n=64-76)\end{array}$ & Mean difference $\pm \mathrm{CI}$ & $P$ value \\
\hline Total PA level (counts/min) & $269(122)$ & $343(132)$ & $-74(-116$ to -31.3$)$ & 0.001 \\
\hline Inactive time (hours/day) & $8.4(1.4)$ & $8.8(1.7)$ & $-0.4(-0.9$ to 0.1$)$ & 0.11 \\
\hline MVPA (min/day) & $25(18)$ & $38(20)$ & $-13(-19$ to -6.3$)$ & $<0.001$ \\
\hline Peak oxygen uptake $\left(\mathrm{ml} \cdot \mathrm{kg}^{-1} \cdot \mathrm{min}^{-1}\right)^{*}$ & $32.2(3.8)$ & $35.6(6.2)$ & $-3.4(-5.5$ to -1.4$)$ & 0.001 \\
\hline BMI $\left(\mathrm{kg} / \mathrm{m}^{2}\right)$ & $27.8(3.3)$ & $26.5(3.8)$ & $1.3(0.2$ to 2.5$)$ & 0.02 \\
\hline Waist circumference $(\mathrm{cm})$ & $100(9)$ & $96(10)$ & $4(0.9$ to 7.4$)$ & 0.01 \\
\hline Glucose (mmol/l) & $5.5(1.2)$ & $5.2(0.5)$ & $0.3(0.04$ to 0.6$)$ & 0.02 \\
\hline Glucose $2 \mathrm{~h}(\mathrm{mmol} / \mathrm{l})$ & $7.7(3.3)$ & $6.1(2.3)$ & $1.6(0.6$ to 2.5$)$ & 0.001 \\
\hline HOMA-IR & $5.1(2.7)$ & $3.2(1.5)$ & $1.9(1.1$ to 2.6$)$ & $<0.001$ \\
\hline Above $2.7 \mathrm{n}(\%)$ & $59(80)$ & $43(56)$ & & \\
\hline MetS, n $(\%) \dagger$ & $47(64 \%)$ & $27(35 \%)$ & & \\
\hline Triglyceride $(\mathrm{mmol} / \mathrm{l})$ & $2.4(2.3)$ & $1.6(0.8)$ & $0.8(0.2$ to 1.3$)$ & 0.009 \\
\hline HDL cholesterol $(\mathrm{mmol} / \mathrm{l})$ & $1.0(0.2)$ & $1.1(0.2)$ & $-0.1(0.1$ to -0.03$)$ & 0.2 \\
\hline LDL cholesterol (mmol/l) & $3.5(0.7)$ & $3.3(0.7)$ & $0.2(-0.04$ to 0.4$)$ & 0.08 \\
\hline Smokers, n (\%) & $17(23)$ & $18(23)$ & & \\
\hline Years living in Norway & $20.0(9.7)$ & $20.8(11.4)$ & $-0.8(-3.6$ to 2.0$)$ & 0.8 \\
\hline
\end{tabular}

Data are adjusted for age

Values are mean $\pm \mathrm{SD}$; standard deviation, if not specified otherwise

$* \mathrm{n}=58$ and $39, \dagger$ Metabolic syndrome was defined according to the international diabetes federation cut off values. CI; confidence intervals, PA; physical activity, MVPA; moderate and vigorous intensity physical activity, MetS; metabolic syndrome, HOMA-IR; homeostasis model assessment - insulin resistance, HDL; high density lipoprotein, LDL; low density lipoprotein

\section{Diet}

Table 5 shows weekly intake of some dietary items. Sixty percent did not consume either fruit or vegetables daily, and $70 \%$ ate fish less than three times per week.

\section{Taxi drivers}

Of the 150 participants 73 (48\%) worked in transport, mainly as taxi drivers $(\mathrm{n}=71)$. Seven other occupational areas were listed in the questionnaire: office job, restaurant/store, teaching, health sector, cleaning, craftsman and sales. Data from these occupations were consolidated into one group and compared with the taxi drivers (Table 5). The taxi drivers were on average three years older than the other occupations group (mean age $=38(\mathrm{SD}=7.1)$ and $35(\mathrm{SD}=7.9)$ respectively, $\mathrm{P}=0.01 ; 95 \% \mathrm{CI}=0.7$ to 5.7 ). Compared to the other occupations group the taxi drivers had a $21.5 \%$ $(95 \% \mathrm{CI}=14.6$ to 28.3$)$ lower PA level and a $9.5 \%$ ( $95 \% \mathrm{CI}=3.7$ to 15.3 ) lower fitness level (Table 6). As shown in Table 6 there were statistical differences between the two groups in most of the blood variables, with a higher disease risk among the taxi drivers. There were no differences in total sugar intake between the two groups. Logistic regression analyses showed that when adjusted for age and education level the taxi drivers had a $3.6(\mathrm{P}=0.001 ; 95 \% \mathrm{CI}=1.6$ to 7.8) higher odds ratio of having the MetS.

The physical activity level hour by hour on workdays and weekends within occupations are shown in Figure 1. The taxi drivers had a significantly lower PA level between the hours 0700 and 1200 (mean counts/ $\min =246(\mathrm{SD}=201)$ vs. $367(\mathrm{SD}=172), \mathrm{P}<0.001 ; 95 \%$ $\mathrm{CI}=-184$ to -58 ), and between 1500 and 1900 (mean counts $/ \min =274(\mathrm{SD}=133)$ vs. $404 \quad(\mathrm{SD}=194)$, $\mathrm{P}<0.001 ; 95 \% \mathrm{CI}=-185$ to -74$)$ on workdays compared to the other occupations group.

\section{Determinants of physical activity}

The most common reported physical activities were; going for walks (39\%), jogging (17\%), biking (16\%), ball playing (13\%) and playing cricket $(12 \%)$. The 


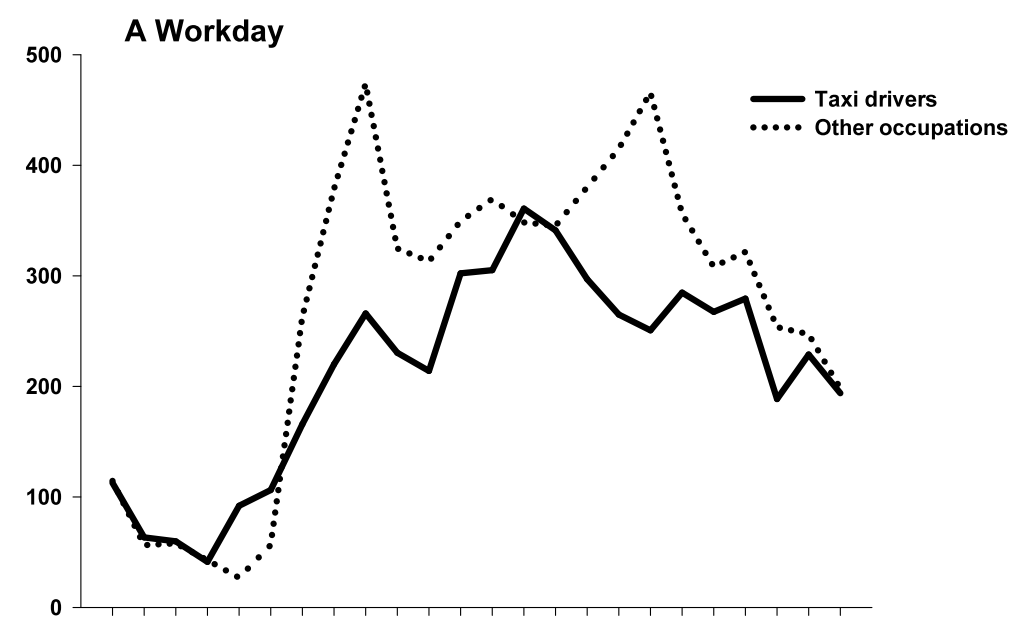

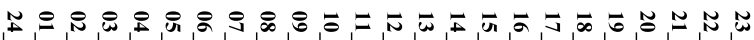

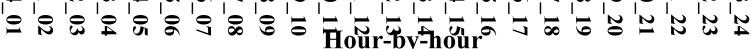

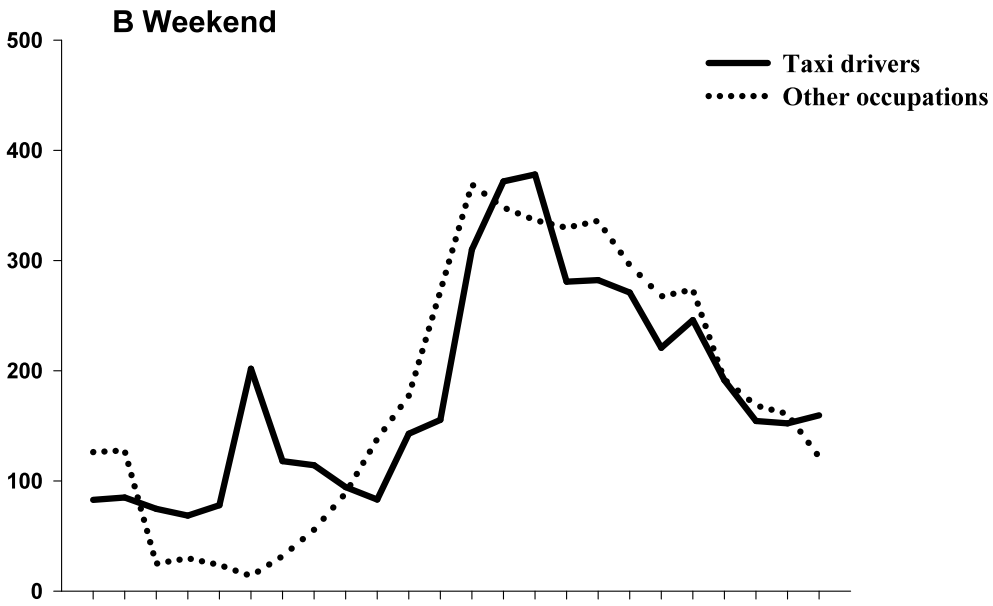

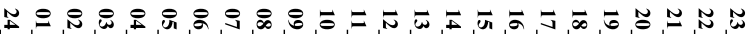

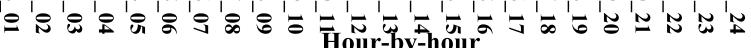

Figure 1. Hour by hour physical activity levels for taxi drivers and other occupations on A) workdays and B) weekends. The plotted values are mean physical activity level (counts/min).

most frequent listed reasons for being physically active were "getting into better shape" (82\%), "not gaining weight" (73\%) and "prevent disease" $(60 \%)$. "Lack of time" was the most prevalent reported barrier towards being physically active, with $92 \%$ reporting this as a relevant barrier. Other common barriers were; "lack of motivation" (86\%), "poor physical fitness" (80\%), "bad weather" (75\%) and "don't know how to do PA" $(65 \%)$.

The mean scores for identity, self-efficacy, social support from family and social support from friends all fell on the center of the scale (Table 7), meaning that the participants only modestly identified themselves as physically active individuals, only modestly believed in their ability to perform physical activity when faced with barriers, and received modestly with support from people close to them for being physically active. Further, participants reported strong positive attitudes towards physical activity (Table 7).
The taxi drivers scored significantly $(\mathrm{P}<0.05)$ higher than those representing the other occupations on the following physical activity barriers: "not the sporty type", "poor physical fitness", "lack of motivation", "feel depressed", "stress", "don't know how to do PA", "don' $t$ find any activities" and "bad health" (data not shown). The taxi drivers also reported a lower selfefficacy for physical activity participation when faced with barriers than participants from the other occupations (Table 7).

\section{DISCUSSION}

In this study we have investigated the physical activity pattern, cardiorespiratory fitness level and important health variables among a group of Pakistani immigrant men living in Oslo, Norway. We found a very low level of PA and cardiorespiratory fitness and a high prevalence of overweight and MetS. Especially the taxi drivers seem to be a group with high risk of diabetes. 
Table 7. Psychosocial characteristics within occupational groups ( $\mathrm{n}=141-146)$.

\begin{tabular}{lccccc}
\hline & Total & Taxi drivers & Other occupations & Mean diff \pm CI & P value \\
\hline Self efficacy & $4.0(1.3)$ & $3.8(1.4)$ & $4.3(1.2)$ & $-0.5(-0.9,-0.02)$ & 0.03 \\
Behavioral control & $4.9(1.3)$ & $4.7(1.3)$ & $5.0(1.1)$ & $-0.3(-0.7,0.0)$ & 0.1 \\
Attitude, evaluative & $6.3(1.0)$ & $6.2(1.2)$ & $6.4(0.9)$ & $-0.1(-0.5,0.2)$ & 0.4 \\
Attitude, affective & $5.6(1.3)$ & $5.6(1.3)$ & $5.5(1.3)$ & $0.1(-0.3,0.5)$ & 0.5 \\
Identity & $3.0(1.0)$ & $2.9(1.0)$ & $3.1(0.9)$ & $-0.2(-0.5,0.1)$ & 0.2 \\
Social support family & $3.3(0.8)$ & $3.2(0.8)$ & $3.3(0.8)$ & $-0.1(-0.3,0.1)$ & 0.4 \\
Social support friends & $3.2(0.9)$ & $3.3(0.8)$ & $3.1(0.9)$ & $0.2(-0.1,0.4)$ & 0.2 \\
\hline
\end{tabular}

Note: Self efficacy, behavioral control and attitude range from 1 to 7 ; Identity and social support range from 1 to 5 ; Perceived social norms range from 1 to 4

Higher scores indicate a greater psychosocial readiness for physical activity

Values are mean $\pm \mathrm{SD}$; standard deviation

$\mathrm{CI}$; confidence interval

\section{PA level}

The average PA level (counts/min) in this study was somewhat lower than reported in a nationally representative study in adults from Norway (34). Whereas the present study found an average of 308 counts $/ \mathrm{min}$, the national study of Anderssen et al. (34) reported a value of 333 for men and 329 for women. The PA level was higher in all age groups except for those more than 70 years. Furthermore, while only four percent of the men in our study reached the PA recommendations, $18 \%$ of the ethnic Norwegians did. Two other nationally representative studies, one from Sweden (35) and one from the USA (36), have been published. The mean counts/ min were 375 (95\% CI = 360 to 390$)$ in the Swedish adult population and $377(95 \% \mathrm{CI}=363$ to 391$)$ among the Americans. Compared to these two studies our participants had PA levels similar to that of the elderly population (60-75 age category). Furthermore, time spent sedentary was somewhat higher among our participants compared to all age groups in the Swedish and the American studies. Objectively measured PA data on south Asian immigrants does not, to our knowledge exist. However, studies using questionnaire data consistently report a low level of PA among immigrants from south Asia both in Norway (9) and the UK $(12,14)$, confirming our results. A low level of PA, high physical inactivity and low cardiorespiratory fitness level are associated with non-communicable diseases and could explain some of the high incidence and prevalence of diabetes and cardiovascular diseases among this immigrant group.

Why the participants in our study have such a low level of PA is difficult to explain. A large part of the men in our sample have sedentary jobs and they have a long working day. The latter possible explanation is in accordance with the high percentage of the sample reporting lack of time as a barrier for being physically active. In addition, exercise or doing recreational activities (i.e. going for walks) may not be as common as among ethnic Norwegians. While only 39\% of our participants were going for walks, $75 \%$ of ethnic Norwegian men do so (37). It might be that cultural attitudes and values held by the south Asian immigrants do not encourage participation in PA, although our results indicate that the participants hold strong positive attitudes towards physical activity. Identifying oneself as a physically active individual, believing in one's ability to perform physical activity, and receiving support for being physically active have repeatedly, in a number of cultural settings, been found to correlate with or mediate physical activity participation (38-40). The modest scores on these variables in the present sample may contribute in the explanation of the low level of PA.

\section{Cardiorespiratory fitness}

To our knowledge, no study measuring the cardiorespiratory fitness level among the general population in Norway has been published. However, when comparing our $\mathrm{VO}_{2}$ peak $\left(\mathrm{ml} \cdot \mathrm{kg}^{-1} \cdot \mathrm{min}^{-1}\right)$ results with data obtained among healthy males in Canada, the maximal oxygen uptake among Canadians was higher in all age groups except for those aged $\geq 60$ years (41). To establish relative $\mathrm{VO}_{2 \max }$ norms in males aged 6-75 years, Shvartz and Reibold (42) performed an extensive literature review of studies in which the maximal oxygen uptake was measured directly in healthy, untrained participants in the USA, Canada and seven European countries. The sample means were used to prepare $\mathrm{VO}_{2 \max }$ norms for all age groups. When using these data our participants would fall into the fitness category "poor" (fitness category 6, where 1 is excellent and 7 is very poor). Lakka et al. (43) found that participants having a maximal oxygen uptake below 35 $\mathrm{ml} \cdot \mathrm{kg}^{-1} \cdot \mathrm{min}^{-1}$ were more likely to have the MetS than those above $35 \mathrm{ml} \cdot \mathrm{kg}^{-1} \cdot \mathrm{min}^{-1}$. This is in accordance to our findings of a significant lower $\mathrm{VO}_{2}$ peak among those with the MetS than those without the syndrome.

\section{Metabolic syndrome and insulin resistance}

Fifty percent of our participants had the MetS. This prevalence is higher than that reported by Hildrum et al. (44) in a study of over 10000 ethnic Norwegians where they observed a prevalence rate of $29 \%$. In the study by Hildrum et al. (44) the prevalence was highly age dependent. However, even in the age group 80-89 years the prevalence of MetS was not higher than $47 \%$. No paper describing the prevalence of MetS among south Asians in Norway exists. However, a study from 
the UK showed a prevalence of $34 \%$ in the age group 40-69 years (using the WHO definition of MetS) in a group of south Asian immigrant men without known diabetes, much higher than among Europeans and other ethnic groups (45). Zahid et al. (46) found a prevalence of $20 \%$ in a sample of 600 Pakistani men living in Pakistan; the mean age was 44 years. The participants in the study by Zahid et al. (46) were from Kharian which is the same area that the participants in our study originally came from. The genetic differences is therefore believed to be small and the discrepancies in prevalence estimates could be due to differences in lifestyle, where the Pakistani men living in Norway are believed to be less physically active, have easier access to energy dense foods and have a higher waist circumference as compared with men living in Kharian.

Insulin resistance was prevalent among our relatively young participants. The mean HOMA-IR score in our study was higher compared to what Vogeser et al. (47) showed in a group of obese (median BMI = 35.7) white Caucasians where the mean HOMA-IR score was 3.5. Urban habits with low PA and high intake of energy dense foods may be enough to induce insulin resistance, even with only mild overweight in south Asians (8). In the multiple regression analyses (data not shown) several factors were associated with HOMA-IR score; waist circumference, sugar intake, total PA level, physical inactivity and having a family member with T2D. Our observations are consistent with other studies showing an independent role of sedentary time (48), sugar intake (49) and total PA (49) on insulin resistance.

\section{Taxi drivers}

The differences in total PA level, MVPA and peak $\mathrm{VO}_{2}$ could explain some of the differences in health between the taxi drivers and the other occupational groups. The health differences could also be due to the occupation per se. Sitting in a taxi all day long means that you don't get small "breaks" in sedentary time. Healy et al. (50) showed that independent of total sedentary time and MVPA, increased breaks in sedentary time were beneficially associated with waist circumference, triglycerides and $2 \mathrm{~h}$ plasma glucose. Many in the other occupations group also have sedentary jobs, with $60 \%$ having an office job; however, they probably have more breaks of the sedentary time. In the other occupation group the men had higher education and also a higher income than the taxi drivers. Higher education could mean better and healthier choices in general, however the odds ratio for having the MetS did not change when adjusting for education level. The health differences could also be due to other factors such as high psychological demands and low control at work (51). Accordingly, the taxi drivers to a higher degree than the other occupations group reported feeling depressed and stressed as barriers for participating in PA. The former group also to a lower extent believed in their ability to be physically active when faced with barriers compared to those representing the other occupations. These differences may reflect a somewhat lower psychological readiness for PA participation among the taxi drivers, which may contribute in explaining the observed difference in PA level.

The data presented are taken from the "Physical activity and minority health study". This study was designed as a randomized controlled trial with the main goal to increase the participants PA level. We excluded therefore eight participants due to a very high PA level and ten diabetics. Also, since the participants volunteered to a PA intervention most of them were motivated to do more PA and are perhaps more active than those who have no interest in PA and therefore did not sign up for this project. When comparing our data with data from "Statistics Norway", the employment rate and education level seem to be slightly higher among the Pakistani immigrant men in our study than generally among the Pakistani immigrant men. Based on the above it is difficult to know whether our participants are representative with respect to physical activity level, cardiorespiratory fitness and risk factors. Therefore, great care should be taken when trying to generalise the results.

\section{CONCLUSIONS}

A low level of objectively measured physical activity, a high degree of physical inactivity, a low level of cardiorespiratory fitness and a high prevalence of MetS and obesity were found in a group of Pakistani immigrant men living in Oslo, Norway. The results emphasize the importance of targeting this immigrant group, especially the taxi drivers to implement preventive measures.

\section{ACKNOWLEDGMENTS}

We wish to thank Eirik Grindaker for his contribution with the data collection. This project has been financially supported by the Norwegian ExtraFoundation for Health and Rehabilitation through EXTRA funds and the Norwegian School of Sport Sciences.

\section{REFERENCES}

1. Alberti KG, Zimmet P, Shaw J. International Diabetes Federation: a consensus on Type 2 diabetes prevention. Diabet Med 2007; 24: 451-463.

2. Riste L, Khan F, Cruickshank K. High prevalence of type 2 diabetes in all ethnic groups, including Europeans, in a British inner city: relative poverty, history, inactivity, or 21 st century Europe? Diabetes Care 2001; 24: 1377-1383. 
3. Bhopal R, Fischbacher C, Vartiainen E, Unwin N, White M, Alberti G. Predicted and observed cardiovascular disease in South Asians: application of FINRISK, Framingham and SCORE models to Newcastle Heart Project data. J Public Health 2005; 27: 93-100.

4. Mather HM, Keen H. The Southall Diabetes Survey: prevalence of known diabetes in Asians and Europeans. Br Med J 1985; 291: 1081-1084.

5. Simmons D, Williams DR, Powell MJ. Prevalence of diabetes in different regional and religious south Asian communities in Coventry. Diabet Med 1992; 9: 428-431.

6. Jenum AK, Holme I, Graff-Iversen S, Birkeland KI. Ethnicity and sex are strong determinants of diabetes in an urban Western society: implications for prevention. Diabetologia 2005; 48: 435-439.

7. McKeigue PM, Shah B, Marmot MG. Relation of central obesity and insulin resistance with high diabetes prevalence and cardiovascular risk in South Asians. Lancet 1991; 337: 382-386.

8. Chandalia M, Abate N, Garg A, Stray-Gundersen J, Grundy SM. Relationship between generalized and upper body obesity to insulin resistance in Asian Indian men. J Clin Endocrinol Metab 1999; 84: 2329-2335.

9. Kumar BN, Meyer HE, Wandel M, Dalen I, Holmboe-Ottesen G. Ethnic differences in obesity among immigrants from developing countries, in Oslo, Norway. Int J Obes 2006; 30: 684-690.

10. Alberti KG, Zimmet P, Shaw J. Metabolic syndrome - a new world-wide definition. A Consensus Statement from the International Diabetes Federation. Diabet Med 2006; 23: 469-480.

11. Bhatnagar D, Anand IS, Durrington PN, Patel DJ, Wander GS, Mackness MI, et al. Coronary risk factors in people from the Indian subcontinent living in west London and their siblings in India. Lancet 1995; 345: 405409.

12. Hayes L, White M, Unwin N, Bhopal R, Fischbacher C, Harland J, Alberti KG. Patterns of physical activity and relationship with risk markers for cardiovascular disease and diabetes in Indian, Pakistani, Bangladeshi and European adults in a UK population. J Public Health Med 2002; 24: 170-178.

13. Misra KB, Endemann SW, Ayer M. Leisure time physical activity and metabolic syndrome in Asian Indian immigrants residing in northern California. Ethn Dis 2005; 15: 627-634.

14. Fischbacher CM, Hunt S, Alexander L. How physically active are South Asians in the United Kingdom? A literature review. J Public Health 2004; 26: 250-258.

15. Holme I, Helgeland A, Hjermann I, Leren P, Lund-Larsen PG. Coronary risk factors in various occupational groups: the Oslo study. Br J Prev Soc Med 1977 31: 96-100.

16. Borgan JK. Occupation and mortality. 1960-2000. SSB, 2009.

17. Statistics Norway. Immigrants from 216 countries 2010. http://www.ssb.no/english/subjects/02/01/10/ innvbef_n/.

18. Hagstromer M, Troiano RP, Sjostrom M, Berrigan D. Levels and patterns of objectively assessed physical activity - a comparison between Sweden and the United States. Am J Epidemiol 2010; 171: 1055-1064.

19. Trost SG, McIver KL, Pate RR. Conducting accelerometer-based activity assessments in field-based research. Med Sci Sports Exerc 2005; 37: S531-S543.

20. Matthews CE, Chen KY, Freedson PS, Buchowski MS, Beech BM, Pate RR, Troiano RP. Amount of time spent in sedentary behaviors in the United States, 2003-2004. Am J Epidemiol 2008; 167: 875-881.

21. Freedson PS, Melanson E, Sirard J. Calibration of the Computer Science and Applications, Inc. accelerometer. Med Sci Sports Exerc 1998; 30: 777-781.

22. Balke B, Ware RW. An experimental study of physical fitness of Air Force personnel. US Armed Forces Med $J$ 1959; 10: 675-688.

23. Matthews DR, Hosker JP, Rudenski AS, Naylor BA, Treacher DF, Turner RC. Homeostasis model assessment: insulin resistance and beta-cell function from fasting plasma glucose and insulin concentrations in man. Diabetologia 1985; 28: 412-419.

24. American Diabetes Association. Diagnosis and classification of diabetes mellitus. Diabetes Care 2010; 33: (Suppl 1): S62-S69.

25. Van Sluijs EM, Van Poppel MN, Twisk JW, Brug J, Van Mechelen W. The positive effect on determinants of physical activity of a tailored, general practice-based physical activity intervention. Health Educ Res 2005; 20: $345-356$.

26. Sallis JF, Grossman RM, Pinski RB, Patterson TL, Nader PR. The development of scales to measure social support for diet and exercise behaviors. Prev Med 1987; 16: 825-836.

27. Fuchs R, Schwarzer R. Selbstwirksamheit zur sportlichen aktivitat: reliabilitat und validitat eines neuen mefinstruments - Self-efficacy towards physical exercise: reliability and validity of a new instrument. Zeitschrift fur Differentielle und Diagnostische Psychologie 1994; 15: 141-154.

28. Courneya KS, Bobick TM. Integrating the theory of planned behavior with the processes and stages of change in the exercise domain. Psychol Sport Exerc 2010; 1: 41-56.

29. Norman P, Smith L. The theory of planned behavior and exercise: an inestigation into the role of prior behavior, behavioral intentions and attitude variability. Eur J Soc Psychol 1995; 25: 403-415. 
30. Charng HW, Piliavin JA, Callero PL. Role identity and reasoned action in the prediction of repeated behavior. Soc Psychol Q 1988; 51: 303-317.

31. WHO expert consultation. Appropriate body-mass index for Asian populations and its implications for policy and intervention strategies. Lancet 2004; 363: 157-163.

32. Bonora E, Targher G, Alberiche M, Bonadonna RC, Saggiani F, Zenere MB, et al. Homeostasis model assessment closely mirrors the glucose clamp technique in the assessment of insulin sensitivity: studies in subjects with various degrees of glucose tolerance and insulin sensitivity. Diabetes Care 2000; 23: 57-63.

33. Ramachandran A, Snehalatha C, Vijay V, Wareham NJ, Colagiuri S. Derivation and validation of diabetes risk score for urban Asian Indians. Diabetes Res Clin Pract 2005; 70: 63-70.

34. Anderssen SA, Hansen BH, Kolle E, Steene-Johannessen J, Børsheim E, Holme I. Physical activity and health among adults and elderly in Norway, 2009.

35. Hagstromer M, Oja P, Sjostrom M. Physical activity and inactivity in an adult population assessed by accelerometry. Med Sci Sports Exerc 2007; 39: 1502-1508.

36. Troiano, R P, Berrigan D, Dodd KW, Masse LC, Tilert T, McDowell M. Physical activity in the United States measured by accelerometer. Med Sci Sports Exerc 2008; 40: 181-188.

37. Statistics Norway. Levekårsundersøkelsen - idrett og friluftsliv. http://www.ssb.no/emner/07/02/50/fritid, 2007.

38. Lorentzen C, Ommundsen Y, Jenum AK, Holme I. The "Romsas in Motion" community intervention: mediating effects of psychosocial factors on forward transition in the stages of change in physical activity. Health Educ Behav 2009; 36: 348-365.

39. Lorentzen C, Ommundsen Y, Holme I. Psychosocial correlates of stages of change in physical activity in an adult community sample. Eur J Sport Sci 2007; 2: 93-106.

40. Sallis JF, Owen N. Physical activity and behavioral medicine, 1999.

41. Nelson MD, Petersen SR, Dlin RA. Effects of age and counseling on the cardiorespiratory response to graded exercise. Med Sci Sports Exerc 2010; 42: 255-264.

42. Shvartz E, Reibold RC. Aerobic fitness norms for males and females aged 6 to 75 years: a review. Aviat Space Environ Med 1990; 61: 3-11.

43. Lakka TA, Laaksonen DE, Lakka HM, Mannikko N, Niskanen LK, Rauramaa R, Salonen JT. Sedentary lifestyle, poor cardiorespiratory fitness, and the metabolic syndrome. Med Sci Sports Exerc 2003; 35: 1279-1286.

44. Hildrum B, Mykletun A, Hole T, Midthjell K, Dahl AA. Age-specific prevalence of the metabolic syndrome defined by the International Diabetes Federation and the National Cholesterol Education Program: the Norwegian HUNT 2 study. BMC Public Health 2007; 7: 220.

45. Tillin T, Forouhi N, Johnston DG, McKeigue PM, Chaturvedi N, Godsland IF. Metabolic syndrome and coronary heart disease in South Asians, African-Caribbeans and white Europeans: a UK population-based cross-sectional study. Diabetologia 2005; 48: 649-656.

46. Zahid N, Claussen B, Hussain A. High prevalence of obesity, dyslipidemia and metabolic syndrome in a rural area in Pakistan, 2008.

47. Vogeser M, Konig D, Frey I, Predel HG, Parhofer KG, Berg A. Fasting serum insulin and the homeostasis model of insulin resistance (HOMA-IR) in the monitoring of lifestyle interventions in obese persons. Clin Biochem 2007; 40: 964-968.

48. Helmerhorst HJ, Wijndaele K, Brage S, Wareham NJ, Ekelund U. Objectively measured sedentary time may predict insulin resistance independent of moderate- and vigorous-intensity physical activity. Diabetes 2009; 58: $1776-1779$.

49. Bremer AA, Auinger P, Byrd RS. Relationship between insulin resistance-associated metabolic parameters and anthropometric measurements with sugar-sweetened beverage intake and physical activity levels in US adolescents: findings from the 1999-2004 National Health and Nutrition Examination Survey. Arch Pediatr Adolesc Med 2009; 163: 328-335.

50. Healy GN, Dunstan DW, Salmon J, Cerin E, Shaw JE, Zimmet PZ, Owen N. Breaks in sedentary time: beneficial associations with metabolic risk. Diabetes Care 2008; 31: 661-666.

51. Gustavsson P, Alfredsson L, Brunnberg H, Hammar N, Jakobsson R, Reuterwall C, Ostlin P. Myocardial infarction among male bus, taxi, and lorry drivers in middle Sweden. Occup Environ Med 1996; 53: 235-240. 